Louisiana State University

LSU Digital Commons

Faculty Publications

Department of Biological Sciences

$6-24-2015$

\title{
Experimental Support for a Single Electron-Transfer Oxidation Mechanism in Firefly Bioluminescence
}

\author{
Bruce R. Branchini \\ Connecticut College \\ Curran E. Behney \\ Connecticut College \\ Tara L. Southworth \\ Connecticut College \\ Danielle M. Fontaine \\ Connecticut College \\ Andrew M. Gulick \\ Hauptman-Woodward Medical Research Institute, Inc.
}

See next page for additional authors

Follow this and additional works at: https://digitalcommons.Isu.edu/biosci_pubs

\section{Recommended Citation}

Branchini, B., Behney, C., Southworth, T., Fontaine, D., Gulick, A., Vinyard, D., \& Brudvig, G. (2015).

Experimental Support for a Single Electron-Transfer Oxidation Mechanism in Firefly Bioluminescence. Journal of the American Chemical Society, 137 (24), 7592-7595. https://doi.org/10.1021/jacs.5b03820

This Article is brought to you for free and open access by the Department of Biological Sciences at LSU Digital Commons. It has been accepted for inclusion in Faculty Publications by an authorized administrator of LSU Digital Commons. For more information, please contact ir@lsu.edu. 


\section{Authors}

Bruce R. Branchini, Curran E. Behney, Tara L. Southworth, Danielle M. Fontaine, Andrew M. Gulick, David J. Vinyard, and Gary W. Brudvig 


\title{
Experimental Support for a Single Electron-Transfer Oxidation Mechanism in Firefly Bioluminescence
}

\author{
Bruce R. Branchini, ${ }^{\dagger}{ }^{\dagger}$ Curran E. Behney, ${ }^{\dagger}$ Tara L. Southworth, $^{\dagger}$ Danielle M. Fontaine, ${ }^{\dagger}$ \\ Andrew M. Gulick, ${ }^{\S} \|$ David J. Vinyard, ${ }^{\star}$ and Gary W. Brudvig \\ ${ }^{\dagger}$ Department of Chemistry, Connecticut College, New London, Connecticut 06320, United States \\ ${ }^{\S}$ Hauptman-Woodward Institute, Buffalo, New York 14203, United States \\ "Department of Structural Biology, University of Buffalo, Buffalo, New York 14203, United States \\ ${ }^{\ddagger}$ Department of Chemistry, Yale University, New Haven, Connecticut 06520, United States
}

Supporting Information

ABSTRACT: Firefly luciferase produces light by converting substrate beetle luciferin into the corresponding adenylate that it subsequently oxidizes to oxyluciferin, the emitter of bioluminescence. We have confirmed the generally held notions that the oxidation step is initiated by formation of a carbanion intermediate and that a hydroperoxide (anion) is involved. Additionally, structural evidence is presented that accounts for the delivery of oxygen to the substrate reaction site. Herein, we report key convincing spectroscopic evidence of the participation of superoxide anion in a related chemical model reaction that supports a single electron-transfer pathway for the critical oxidative process. This mechanism may be a common feature of bioluminescence processes in which light is produced by an enzyme in the absence of cofactors.

$\mathrm{T}$ he familiar yellow-green glow of the firefly lantern is a beautiful example of bioluminescence. The biochemical process for the firefly luciferase (Luc) catalyzed conversion of substrates beetle luciferin $\left(\mathrm{LH}_{2}\right)$ and Mg-ATP into light, including the identification of the emitter oxyluciferin $\left(\mathrm{OxyLH}_{2}\right)$ and the inhibitory side product dehydroluciferylAMP (L-AMP), was established ${ }^{1} \sim 60$ years ago by McElroy, White, and others working with the enzyme from Photinus pyralis. Bioluminescence is the result of two Luc-catalyzed halfreactions (Scheme 1): (1) the production of luciferyl-adenylate $\left(\mathrm{LH}_{2}-\mathrm{AMP}\right)$ and $(2)$ the reaction of $\mathrm{LH}_{2}$-AMP with $\mathrm{O}_{2}$ to produce $\mathrm{OxyLH}_{2}$ in an electronically excited state. According to our biochemical and crystallographic studies, ${ }^{2,3}$ the chemistries take place in two distinct Luc conformations, related by an $\sim 140^{\circ}$ rotation of the $\mathrm{C}$-terminal domain, that essentially creates 2 distinct active sites. In fact, Luc is a member of the large acyl-CoA synthetases, non-ribosomal peptide synthetase adenylation domains, and luciferases (ANL) superfamily of enzymes ${ }^{4}$ that form the adenylates of carboxylate substrates, e.g., acetate and the amino acids, that are substrates for subsequent thioester-forming reactions. The domain alternation mechanism ${ }^{4}$ that describes the overall chemical reactions of the ANL superfamily enzymes provides a fine example of the structure-function theme in biochemistry. While Luc possesses a CoA binding site and can convert $\mathrm{LH}_{2}$-AMP and L-AMP into the corresponding CoA
Scheme 1. Original Mechanism of Luc Bioluminescence

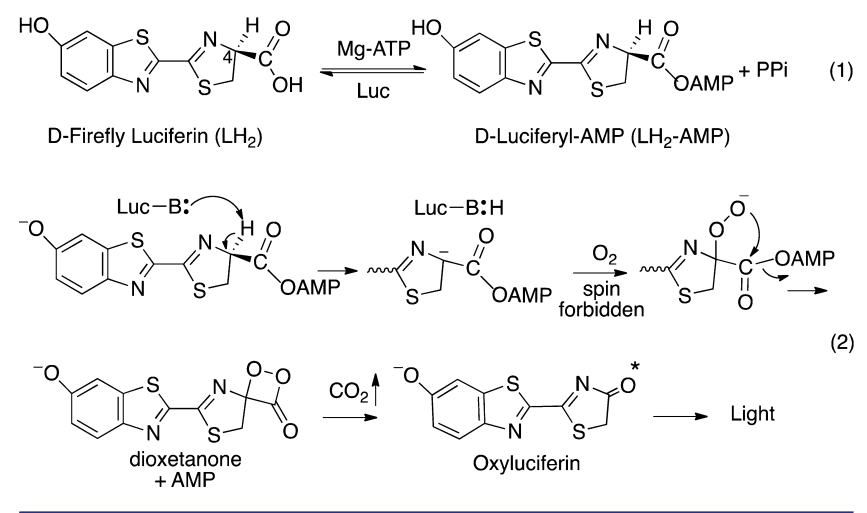

thioesters, ${ }^{5,6}$ the light yielding oxidation of $\mathrm{LH}_{2}$-AMP, the second Luc half-reaction, does not require CoA, metal ions, or other coenzymes. The mechanism of this uncommon cofactorindependent Luc oxygenase function that distinguishes the luciferases from the other superfamily members is the focus here.

The generally accepted mechanism of Luc-catalyzed light production is based on the formation of a key dioxetanone intermediate (Scheme 1), which was inferred from ${ }^{18} \mathrm{O}$ labeling results of chemiluminescence model studies. ${ }^{7,8}$ Dioxetanone intermediates are commonly considered to be sources of bioluminescence. ${ }^{9}$ As proposed by White et al., the oxidative Luc reaction is initiated when a presumed active site base abstracts the $\mathrm{C} 4$ proton of $\mathrm{LH}_{2}$-AMP producing a carbanion (Scheme 1). The $\mathrm{C} 4$ anion, which can be delocalized through the adjacent carbonyl, is thought to react with $\mathrm{O}_{2}$ to form a peroxy anion intermediate that is rapidly converted into the dioxetanone as AMP is released. Because it is problematic that the peroxide must form from unactivated $\mathrm{O}_{2}$ in a spin forbidden process, ${ }^{10}$ we investigated two alternative mechanisms: (1) a radical mechanism ${ }^{3}$ based on $\mathrm{O}_{2}$ abstraction of a $\mathrm{C} 4 \mathrm{H}$ atom (Scheme 2a) and (2) a single electron-transfer (SET) mechanism ${ }^{11}$ involving superoxide anion $\left({ }^{\bullet} \mathrm{OO}^{-}\right.$) formation (Scheme $2 \mathrm{~b}$ ).

Two important features are common to all three of the oxidative mechanisms: (1) the delivery of $\mathrm{O}_{2}$ to the $\mathrm{C} 4$ carbon of the $\mathrm{LH}_{2}$-AMP and (2) the formation of a hydroperoxide (anion)

Received: April 13, 2015

Published: June 9, 2015 
Scheme 2. Radical and SET Oxidation Mechanisms

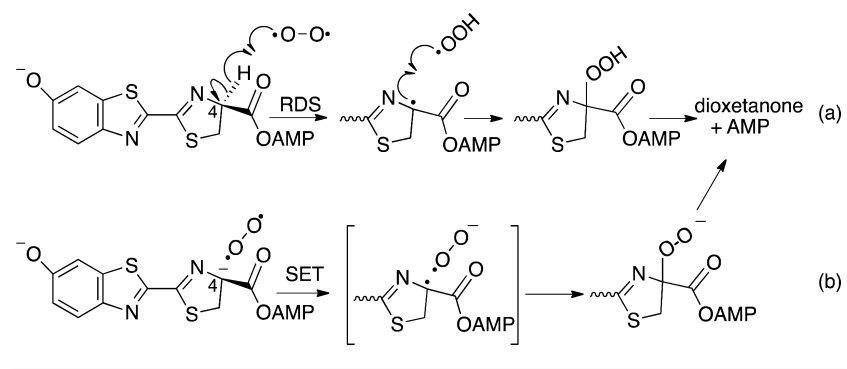

intermediate. In the structure of a cross-linked variant ${ }^{2,3}$ of wildtype P. Pyralis Luc (PpyWT), the pantetheine tunnel seen in other ANL enzymes is intact (Figure 1). At the end of this tunnel

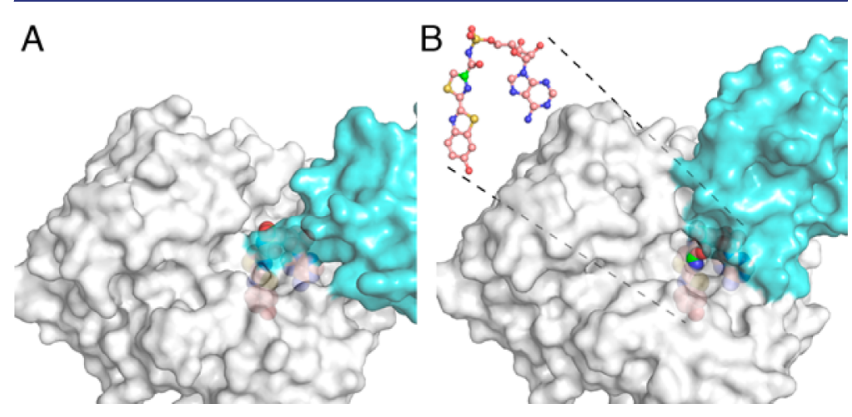

Figure 1. View down the putative $\mathrm{O}_{2} /$ pantetheine tunnel. $P$. pyralis luciferases are shown in the same orientation in the (A) adenylation and (B) oxidative conformations. DLSA, a $\mathrm{LH}_{2}$-AMP analog, is bound in the active site of both structures. The $\mathrm{C} 4$ carbon is highlighted in green. The inset shows the orientation of the DLSA molecule of panel B in ball-andstick representation.

is the C4 carbon of DLSA, ${ }^{12}$ a stable $\mathrm{N}$-acyl sulfamate analog of $\mathrm{LH}_{2}$-AMP. Luc contains a conserved glycine residue, Gly446, which lines the tunnel. In related enzymes, this glycine forms a distorted $\beta$-sheet interaction with the amide nitrogens of the pantethene moiety. A G446I mutation in PpyWT specifically impairs the oxidative reaction, ${ }^{13}$ suggesting that $\mathrm{O}_{2}$ approaches the intermediate through this same tunnel. Side chain rotation of active site residue His 245 further expands the tunnel for access to C4 (Figure 1) of the adenylate. We believe that the initiation of the Luc half-reaction is coupled to the His 245 side chain motion that provides $\mathrm{O}_{2}$ access to the $\mathrm{C} 4$ carbon of $\mathrm{LH}_{2}$-AMP (Figure 1). The proximity of $\mathrm{O}_{2}$ to His 245 in PpyWT was established previously by active site-directed photo oxidation studies. ${ }^{14}$

We initiated this study by making the $\mathrm{H} 245 \mathrm{C}$ variant (Table S1) of PpyWT reasoning that a Luc-generated hydroperoxide intermediate could oxidize the side chain thiol providing evidence for the involvement of this peroxy species in the oxidation process. Modeling studies suggested that the $S$ atom of the introduced Cys residue could approach the peroxide within a distance of $\sim 2.9 \AA$ (Figure S2). The H245C enzyme retained nearly complete adenylation activity; however, the overall specific activity and the oxidative half-reaction rate (based on photon production) were $<1 \%$ of the PpyWT values (Table S2). The basis for the lack of bioluminescence activity was the low (3\%) yield of $\mathrm{OxyLH}_{2}$.

Encouragingly, in addition to obtaining the expected L-AMP (24\%) side product, we observed a new major $(72 \%)$ product 4hydroxyluciferyl-AMP ( $\left.\mathrm{HO}-\mathrm{LH}_{2}-\mathrm{AMP}\right)$ that formed only in the H245C-catalyzed reaction (Scheme 3 ). We determined that Cys245 was selectively and concomitantly oxidized to the
Scheme 3. H245C-Catalyzed 4-HO- $\mathrm{LH}_{2}$-AMP Formation

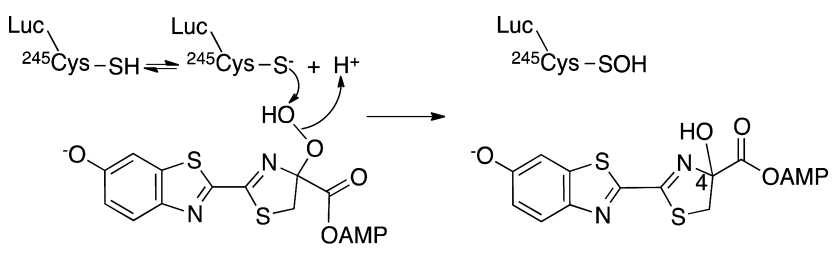

corresponding sulfenic acid and rationalized these findings, which support the involvement of a hydroperoxide intermediate in the oxidation process (Supporting Information, SI), according to Scheme 3.

Next we determined that the kinetic isotope effect $\left(k_{\mathrm{H}} / k_{\mathrm{D}}\right)$ for the reaction of PpyWT with 4-deutero-D- $\mathrm{LH}_{2}-\mathrm{AMP}$ was $2.1 \pm 0.2$ (Table S3). Our result is consistent with the value (2.3) reported ${ }^{15}$ by McCapra for the overall bioluminescence reaction and with the rate-determining step (RDS) of the oxidative chemistry requiring removal of either a $\mathrm{H}^{+}$or a $\mathrm{H}$ atom from $\mathrm{C} 4$ of $\mathrm{LH}_{2}$-AMP. While rate-limiting $\mathrm{C} 4$ carbanion formation is consistent with the original and SET mechanisms, only the radical mechanism requires $\mathrm{O}_{2}$ to participate directly in the RDS (Schemes 1 and 2). This is because the abstraction of a $\mathrm{H}$ atom by $\mathrm{O}_{2}$ would be expected to have a relatively high $(\sim 170-210$ $\mathrm{kJ} / \mathrm{mol}$ ) activation energy. ${ }^{16}$ With this in mind, we undertook an experiment in which PpyWT (200 nM) was incubated with $\mathrm{LH}_{2}$ AMP $(100 \mathrm{nM})$ for $30 \mathrm{~s}$ at $22^{\circ} \mathrm{C}$ in $100 \mathrm{mM}$ sodium phosphate buffer, pH $7.8(\mathrm{NaPB})$ under anaerobic conditions. During this time no light emission was observed. However, when the mixture $(0.25 \mathrm{~mL})$ was rapidly injected into $0.25 \mathrm{~mL}$ of aerated $\mathrm{NaPB}$ in a reaction tube placed in a luminometer, a rapid burst of light was emitted characterized by a $90 \mathrm{~ms}$ rise time to maximum intensity (Figure 2). A control reaction performed by injecting $0.25 \mathrm{~mL}$ of

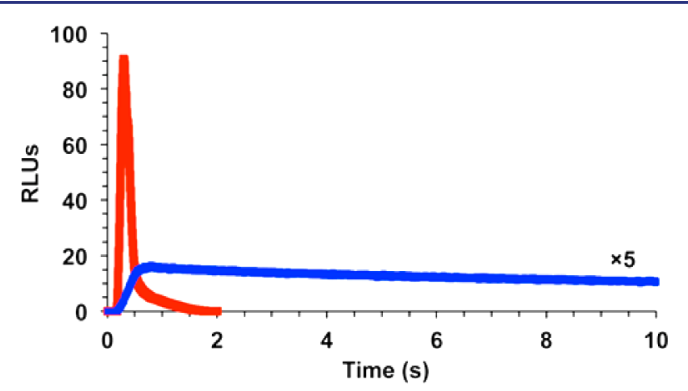

Figure 2. Bioluminescence emission profiles produced by (red) injection of an anaerobic mixture of PpyWT plus $\mathrm{LH}_{2}$-AMP into aerated $\mathrm{NaPB}$ and (blue) injection of PpyWT in aerated $\mathrm{NaPB}$ into a solution of $\mathrm{LH}_{2}$-AMP in aerated NaPB. Final concentrations of enzyme and substrate were 100 and $50 \mathrm{nM}$, respectively.

$200 \mathrm{nM}$ PpyWT in aerated NaPB into $0.25 \mathrm{~mL}$ of a solution of $100 \mathrm{nM} \mathrm{LH}_{2}$-AMP in aerated $\mathrm{NaPB}$ that had stood at $22{ }^{\circ} \mathrm{C}$ for $30 \mathrm{~s}$ emitted approximately the same amount of light, but at a much slower rate (400 ms rise time) (Figure 2). These results were interpreted to indicate that the RDS had occurred prior to the addition of $\mathrm{O}_{2}$, a result that is consistent with the original and SET mechanisms, but not the radical-based process (Schemes 1 and 2). Furthermore, the results suggested that the anaerobic incubation enabled the buildup of a Luc-stabilized C4 carbanionic intermediate. To test this notion, we performed experiments (SI) in which 4-deutero- $\mathrm{LH}_{2}$-AMP $(3.5 \mu \mathrm{M})$ was incubated with or without PpyWT $(7.0 \mu \mathrm{M})$ for $30 \mathrm{~s}$ at $22^{\circ} \mathrm{C}$ in $\mathrm{NaPB}$ under anaerobic conditions. The mixtures were then 
quenched with $10 \% \mathrm{v} / \mathrm{v}$ acetonitrile- $0.25 \mathrm{~N} \mathrm{HCl}$ and analyzed by ESI/MS. With enzyme present, 95\% C4 H-D exchange of the recovered adenylate was observed, while the control reaction produced $<1 \%$ exchange. The results of these experiments taken together are consistent with the Luc-assisted formation of a C4 carbanionic intermediate as required by the original and SET mechanisms.

We next sought to take advantage of the major difference between the original and SET oxidation mechanisms-the involvement of superoxide anion in the latter. We turned to electron paramagnetic resonance (EPR), a spectroscopic technique that unambiguously detects unpaired electron species directly or through the use of spin trapping reagents.

Probably because of the expected short lifetime of enzymegenerated superoxide anion and/or the inaccessibility of spin trapping reagents to the active site, we were unable to detect EPR signals from bioluminescence reactions. So, we turned to the well-established chemical model reaction ${ }^{17}$ shown in Scheme 4.

Scheme 4. Oxidation of $\mathrm{LH}_{2}-\mathrm{OMe}$

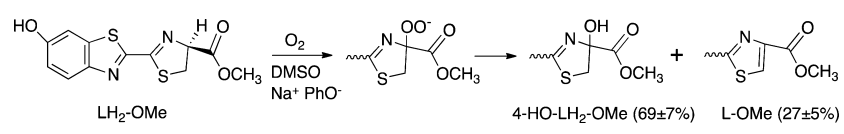

Under mild alkaline conditions the methyl ester of luciferin $\left(\mathrm{LH}_{2}-\mathrm{OMe}\right)$ is oxidized via a hydroperoxide intermediate into a mixture of 4-hydroxyluciferin methyl ester (4-HO- $\mathrm{LH}_{2}-\mathrm{OMe}$ ) and dehydroluciferin methyl ester (L-OMe). Presumably because of the poor leaving group ability of methoxide ion, $\mathrm{OxyLH}_{2}$ and light are not produced. The key feature of this reaction is that a hydroperoxide is formed from a $\mathrm{C} 4$ anion as required by the original and SET mechanisms. Because we could use solvent DMSO to obtain relatively high concentrations of $\mathrm{LH}_{2}$-OMe (8.5 mM) and 5-tert-butoxycarbonyl 5-methyl-1pyrroline $\mathrm{N}$-oxide (BMPO) $(85 \mathrm{mM})$, a superior superoxide anion spin trapping reagent, ${ }^{18}$ we reasoned that if the model reaction proceeded via a SET mechanism, we could use EPR to demonstrate the involvement of superoxide anion. This, in turn, would enable us to use the model chemistry results to support the Luc catalyzed oxidation mechanism. We began by repeating the reaction shown in Scheme 4 with a 2.4 mol excess of sodium phenoxide over methyl ester (SI). Using ESI/MS methods, we documented a product distribution very similar to the literature report. ${ }^{17}$ Interestingly, we also detected the hydroperoxide ( $\sim 4 \%$ ) confirming the occurrence of this intermediate in the model reaction. Then we performed EPR studies on the model reaction along with a series of controls (Figure 3). EPR spectroscopy using the spin trap $\mathrm{BMPO}^{18}$ confirmed the presence of superoxide anion. As shown in Figure 3a, the reaction of $\mathrm{LH}_{2}-\mathrm{OMe}$ and sodium phenoxide in the presence of $\mathrm{BMPO}$ resulted in the formation of the $\mathrm{BMPO}+{ }^{\circ} \mathrm{OO}^{-}$adduct (Scheme 5). The BMPO-OO- EPR spectrum is an overlapping "doublet of triplets" arising from hyperfine interactions from ${ }^{14} \mathrm{~N}$ $\left(\mathrm{a}_{\mathrm{N}}=14.1 \mathrm{G}\right)$ and ${ }^{1} \mathrm{H}\left(\mathrm{a}_{\mathrm{H}}=20.8 \mathrm{G}\right)$. These hyperfine constants measured in DMSO are similar to values from previous studies of ${\mathrm{BMPO}-\mathrm{OO}^{-}}^{-}$in water. ${ }^{19}$ The simulation in Figure $3 \mathrm{~b}$ assumes a

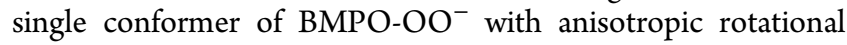
correlation times. Detailed simulation parameters are provided in the SI. Control experiments (Figure $3 \mathrm{c}-\mathrm{g}$ ) show that BMPO$\mathrm{OO}^{-}$is formed only when $\mathrm{LH}_{2}-\mathrm{OMe}$, sodium phenoxide, and $\mathrm{BMPO}$ are all present.

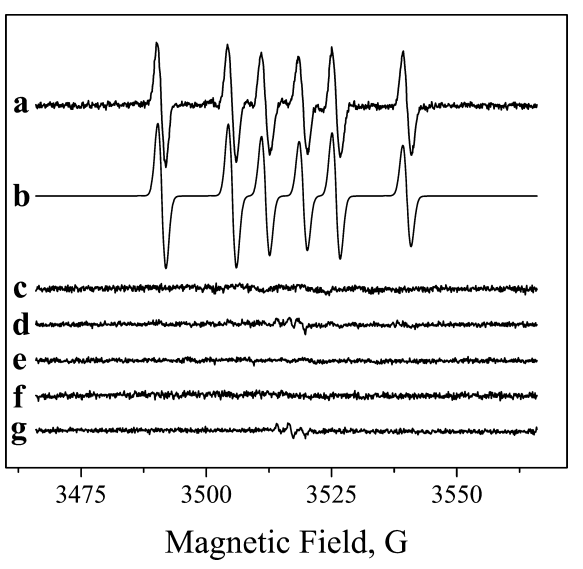

Figure 3. EPR spectra of BMPO-OO- in DMSO at $19.5^{\circ} \mathrm{C}$. (a) $\mathrm{LH}_{2}^{-}$ $\mathrm{OMe}+$ sodium phenoxide + BMPO, (b) simulation (see $\mathrm{SI}$ ), (c) $\mathrm{LH}_{2}-$ $\mathrm{OMe}+\mathrm{BMPO},(\mathrm{d})$ sodium phenoxide + BMPO, (e) BMPO only, (f) $\mathrm{LH}_{2}-\mathrm{OMe}+$ sodium phenoxide, and $(\mathrm{g})$ sodium phenoxide only.

\section{Scheme 5. Generation of BMPO-OO-}

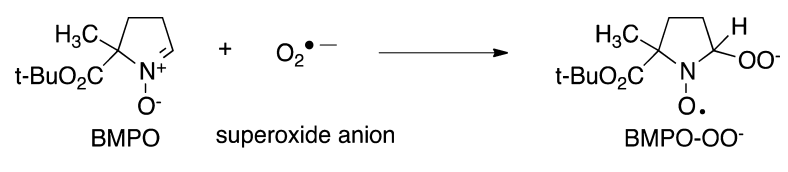

The results reported here provide biochemical data confirming a peroxy intermediate in Luc bioluminescence and rare spectroscopic evidence for the involvement of superoxide anion in a bioluminescence model reaction. Additionally, it is likely that the pantethine tunnel and His245 expedite superoxide formation by orienting and directing $\mathrm{O}_{2}$ very close to the reaction site (Figure 1). We believe that our model results provide a compelling basis for the Luc-catalyzed SET oxidation mechanism (Scheme 2b) rather than the spin forbidden process of the original and generally accepted process (Scheme 1). Luc bioluminescence provides another example of the "substrateassisted oxygenases" concept ${ }^{20}$ in which the organic substrate drives the oxidation in the absence of cofactors. The SET mechanism has been proposed for the coelenterazine-obelin bioluminescence reaction ${ }^{21,22}$ and may also be operative in the newly described ${ }^{23,24}$ earthworm light emission process that likely proceeds via an acyl adenylate intermediate and in bacterial bioluminescence. It will be interesting to see if the SET mechanism of substrate oxidation to form a corresponding hydroperoxide intermediate is a unifying feature of the diverse bioluminescence world and if enzyme variants that further stabilize key carbanion intermediates and superoxide ion can improve bioluminescence efficiency.

\section{ASSOCIATED CONTENT}

\section{S Supporting Information}

Experimental details of $\mathrm{H} 245 \mathrm{C}$ mutagenesis and reaction with $\mathrm{LH}_{2}$-AMP; protein characterization; LC/MS analyses; substrate syntheses; kinetic isotope effects; anaerobic experiments and product analyses; model oxidation reaction; additional discussion material; and EPR spectroscopy of model and luciferase reactions. The Supporting Information is available free of charge on the ACS Publications website at DOI: 10.1021/jacs.5b03820.

\section{AUTHOR INFORMATION}

\section{Corresponding Author}

*brbra@conncoll.edu 


\section{Notes}

The authors declare no competing financial interest.

\section{ACKNOWLEDGMENTS}

We gratefully acknowledge the financial support provided by the Air Force Office of Scientific Research FA9550-14-1-0100 (B.R.B.), the National Science Foundation MCB-1410390 (B.R.B.) and the Hans \& Ella McCollum '21 Vahlteich Endowment (B.R.B.). The EPR spectroscopy work was supported by the Department of Energy, Office of Basic Energy Sciences, Division of Chemical Sciences grant DE-FG0205ER15646 (D.J.V. and G.W.B.). We also thank Justin G. Stroh for performing mass spectrometry and Marc Zimmer for the molecular modeling studies.

\section{REFERENCES}

(1) DeLuca, M. Adv. Enzymol. 1976, 44, 37.

(2) Branchini, B. R.; Rosenberg, J. C.; Fontaine, D. M.; Southworth, T. L.; Behney, C. E.; Uzasci, L. J. Am. Chem. Soc. 2011, 133, 11088.

(3) Sundlov, J. A.; Fontaine, D. M.; Southworth, T. L.; Branchini, B. R.; Gulick, A. M. Biochemistry 2012, 51, 6493.

(4) Gulick, A. M. ACS Chem. Biol. 2009, 4, 811.

(5) Fraga, H.; Esteves Da Silva, J. C. G.; Fontes, R. ChemBioChem 2004, 5, 110.

(6) Fraga, H.; Esteves da Silva, J. C. G.; Fontes, R. Tetrahedron Lett. 2004, 45, 2117.

(7) White, E. H.; Rapaport, E.; Seliger, H. H.; Hopkins, T. A. Bioorg. Chem. 1971, 1, 92.

(8) White, H. E.; Miano, J. D.; Umbreit, M. J. Am. Chem. Soc. 1975, 97, 198.

(9) Navizet, I.; Liu, Y. J.; Ferre, N.; Roca-Sanjuan, D.; Lindh, R. ChemPhysChem 2011, 12, 3064.

(10) Min, C. G.; Ren, A. M.; Li, X. N.; Guo, J. F.; Zou, L. Y.; Sun, Y.; Goddard, J. D.; Sun, C. C. Chem. Phys. Lett. 2011, 506, 269.

(11) Mofford, D. M.; Reddy, G. R.; Miller, S. C. Proc. Natl. Acad. Sci. U. S. A. 2014, 111, 4443 .

(12) Branchini, B. R.; Murtiashaw, M. H.; Carmody, J. N.; Mygatt, E. E.; Southworth, T. L. Biorg. Med. Chem. Lett. 2005, 15, 3860.

(13) Branchini, B. R.; Southworth, T. L.; Murtiashaw, M. H.; Wilkinson, S. R.; Khattak, N. F.; Rosenberg, J. C.; Zimmer, M. Biochemistry 2005, 44, 1385.

(14) Branchini, B. R.; Magyar, R. A.; Marcantonio, K. M.; Newberry, K. J.; Stroh, J. G.; Hinz, L. K.; Murtiashaw, M. H. J. Biol. Chem. 1997, 272, 19359.

(15) McCapra, F.; Gilfoyle, D. J.; Young, D. W.; Church, N. J.; Spencer, P. In Bioluminescence and Chemiluminescence: Fundamentals and Applied Aspects; Campbell, A. K., Kricka, L. J., Stanley, P. E., Eds.; John Wiley and Sons: Chichester, 1994; p 387.

(16) Fossey, J.; Lefort, D.; Sorba, J. Free Radicals in Organic Chemistry; John Wiley \& Sons: Chichester, 1995.

(17) White, E. H.; Steinmetz, M. G.; Miano, J. D.; Wildes, P. D.; Morland, R. J. Am. Chem. Soc. 1980, 102, 3199.

(18) Zhao, H. T.; Joseph, J.; Zhang, H.; Karoui, H.; Kalyanaraman, B. Free Radical Biol. Med. 2001, 31, 599.

(19) Bacic, G.; Spasojevic, I.; Secerov, B.; Mojovic, M. Spectrochim. Acta, Part A 2008, 69, 1354.

(20) Fetzner, S.; Steiner, R. A. Appl. Microbiol. Biotechnol. 2010, 86, 791.

(21) Kondo, H.; Igarashi, T.; Maki, S.; Niwa, H.; Ikeda, H.; Hirano, T. Tetrahedron Lett. 2005, 46, 7701.

(22) Eremeeva, E. V.; Natashin, P. V.; Song, L.; Zhou, Y. G.; van Berkel, W. J. H.; Liu, Z. J.; Vysotski, E. S. ChemBioChem 2013, 14, 739.

(23) Petushkov, V. N.; Dubinnyi, M. A.; Tsarkova, A. S.; Rodionova, N. S.; Baranov, M. S.; Kublitski, V. S.; Shimomura, O.; Yampolsky, I. V. Angew. Chem., Int. Ed. 2014, 53, 5566.
(24) Dubinnyi, M. A.; Kaskova, Z. M.; Rodionova, N. S.; Baranov, M. S.; Gorokhovatsky, A. Y.; Kotlobay, A.; Solntsev, K. M.; Tsarkova, A. S.; Petushkov, V. N.; Yampolsky, I. V. Angew. Chem., Int. Ed. 2015, 54, 7065. 